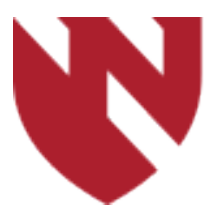

September 2020

\title{
The Advantages of a Rural Residency Rotation in Otolaryngology Training
}

\author{
Mark Miller \\ University of Nebraska Medical Center \\ Paul Brosnihan \\ University of Nebraska Medical Center \\ Christie Barnes \\ University of Nebraska Medical Center \\ Matthew Johnson \\ University of Nebraska Medical Center \\ Jayme Dowdall \\ University of Nebraska Medical Center
}

Tell us how you used this information in this short survey.

Follow this and additional works at: https://digitalcommons.unmc.edu/gmerj

Part of the Higher Education Commons, and the Medicine and Health Sciences Commons

\section{Recommended Citation \\ Miller, M., Brosnihan, P., Barnes, C., Johnson, M., , Dowdall, J. The Advantages of a Rural Residency Rotation in Otolaryngology Training. Graduate Medical Education Research Journal. 2020 Sep 29; 2(1). https://digitalcommons.unmc.edu/gmerj/vol2/iss1/24}

This Conference Proceeding is brought to you for free and open access by DigitalCommons@UNMC. It has been accepted for inclusion in Graduate Medical Education Research Journal by an authorized editor of DigitalCommons@UNMC.For more information, please contact digitalcommons@unmc.edu. 


\section{The Advantages of a Rural Residency Rotation in Otolaryngology Training Creative Commons License \\ (c) $(1) \Theta(9$}

This work is licensed under a Creative Commons Attribution-Noncommercial-No Derivative Works 4.0 License. 
The Association of Severity of COPD and Severity of OSA: A Retrospective Analysis

Mollie Brittan ${ }^{1}$, Maureen McElligott ${ }^{2}$, Kaeli Samson ${ }^{3}$, Valerie Press ${ }^{4}$, Michael Summers ${ }^{2}$, John Harrington ${ }^{2}$, Nancy Stewart ${ }^{2}$

${ }^{1}$ University of Nebraska Medical Center, Department of Internal Medicine

${ }^{2}$ University of Nebraska Medical Center, Department of Pulmonary, Critical Care, and Sleep Medicine

${ }^{3}$ University of Nebraska Medical Center, College of Public Health, Department of Biostatistics

${ }^{4}$ University of Chicago, Department of Internal Medicine, Chicago, IL

\section{Mentor: Michael Summers}

Program: Pulmonary, Critical Care, and Sleep Medicine

Type: Original Research

Background: Chronic obstructive pulmonary disease (COPD) affects over 24 million adults in the United States and the 3rd leading cause of morbidity and mortality. A common unrecognized factor that may exacerbate COPD is concomitant Obstructive Sleep Apnea (OSA). OSA is a common sleep disorder, affecting approximately 1 in 4 adults. Correlation between severity of the two remains largely unexplored, and is the aim of this study.

Methods: In a retrospective chart analysis of diagnostic in-lab polysomnography (PSG), pulmonary function testing (PFT), and ICD coding, we determined patients with concomitant OSA and COPD. Patients were included had a diagnostic PSG and PFTs performed within the same calendar year. Demographics, health status, and health care system usage were also collected. COPD severity was classified using FEV1 GOLD criteria. Associations were assessed using Pearson correlations, and statistical models were generated evaluating the association between severities of OSA and COPD, health system usage, and positive airway pressure compliance, adjusting for confounders. All analyses were performed using SAS software version 9.4 (SAS Institute Inc., Cary, NC).

Results: From December 2015 to November of 2018, 316 patients were identified with ICD codes to have both COPD and OSA. The majority were female $(56.3 \%)$, Caucasian $(79.0 \%)$, with a mean age of 64 (SD: 10.7). Out of those patients with PFT data available $(\mathrm{n}=273)$, over one third had mild COPD (38\%), with the remaining having moderate, moderately severe, severe, and very severe $(16.5 \%, 16.1 \%, 13.9 \%$, and $5.8 \%$, respectively). Although they carried a diagnosis of COPD, 26 patients $(9 \%)$ had an FEV1 $>100 \%$, possibly representing a physiologic variant. OSA severity was severe in 115 (36.4\%), mild in $111(35.1 \%)$, and moderate in $90(28.5 \%)$ patients. No significant correlation between severities of COPD and OSA $(r=-0.07, p=0.25)$ was noted, even after adjusting for potential confounders $(p=0.99)$. OSA and FEV were not significantly associated with readmissions or ED visits ( $p$ 's $>0.20$ ), however AHI was associated with PAP compliance $(\mathrm{p}=0.003)$.

Conclusion: OSA and COPD are two common conditions, each associated with a high morbidity and mortality, both commonly co-existing within the same patient. Our study did not find an association between the severity of these two disease states. More research is needed in this area to study any potential correlation between the severity of these diseases.

https://doi.org/10.32873/unmc.dc.gmerj.2.1.022

\section{The Advantages of a Rural Residency Rotation in Otolaryngology Training}

Mark Miller ${ }^{1}$, Paul Brosnihan ${ }^{2}$, Christie Barnes ${ }^{1}$, Matthew Johnson', Jayme Dowdall'

${ }^{1}$ University of Nebraska Medical Center, Department of Otolaryngology - Head and Neck Surgery

${ }^{2}$ University of Nebraska Medical Center, College of Medicine

Mentor: Jayme Dowdall

Program: Otolaryngology - Head and Neck Surgery

Type: Original Research

Background: Rural residency rotations have played a significant role in encouraging surgical residents to pursue a career in a rural community. This study reviews the resident caseload of an otolaryngology residency rural rotation in comparison with a traditional primary university-based urban location.

Methods: The Accreditation Council for Graduate Medical Education (ACGME) case log system was used to review cases logged by residents during their rural rotations from July 2017 to December 2018. Case log data were compared with a matched resident of similar training experience on the university service during the same time period.

Results: Rural residents reported more cases than their urban-based counterparts (1143 vs 690 cases). Junior residents had over double the number of cases in rural practice (400) compared to junior residents on the university service (168). The university service was much stronger on H\&N Neck ( 54 vs. 28 cases), Larynx (39 vs 8) and Endoscopy (92 vs 42 ). In contrast, the rural rotation provided substantially more Endocrine cases (103 vs 47 ) and comparable salivary cases (23 vs 21 ) compared to the university service.

Conclusion: This study describes a surgically robust rotation in rural medicine and highlights the possibility of obtaining exposure to a surgical practice unique to a rural setting. By participating in high volume surgical rural residency rotations, trainees may better understand the otolaryngologic needs of a rural population. Future work is needed to determine if rural rotations impact future practice decisions.

https://doi.org/10.32873/unmc.dc.gmerj.2.1.023 